\title{
Idiopathic Neonatal Haemochromatosis: A Case Report
}

\author{
Besharat $\mathbf{S}^{1}$, Alaee $\mathrm{E}^{2}$, Zahedpasha $\mathrm{Y}^{3}$
}

${ }^{1}$ Dr. Sima Besharat, MD, ${ }^{2}$ Dr. Ehsan Alaee MD Neonatalogist, Department of Paediatrics and Neonatology, Golestan University of Medical Sciences, Gorgan, Iran, ${ }^{3} \mathrm{Dr}$. Yadollah Zahedpasha MD, Paediatric Research Center, Amirkola Children Hospital, Department of Paediatric, School of Medicine, Babol University of Medical Sciences, Babol, Iran.

Address for correspondence: Dr. Ehsan Alaee, E-mail: ealaee@yahoo.com

\begin{abstract}
A case of neonatal hemochromatosis is reported in a premature 35-week infant who presented at birth with coffee ground vomiting and gradual appearance of grayish icter and colorless stool. Neonatal hemochromatosis was confirmed by elevated ferritin levels and extrahepatic siderosis detected in liver biopsy.
\end{abstract}

Key words: Neonatal hemochromatosis, Liver biopsy, Serum ferritin

\section{Introduction}

Iron is a crucially important element in normal cellular function and its homeostasis should be tightly controlled. Disruption of this regulation and abnormal intestinal absorption of iron will lead to cellular toxicity, tissue injury, and organ fibrosis via the deposition of this iron in parenchymal cells of a number of different organs such as the heart, pancreas, and liver ${ }^{1}$.

Iron-generated oxyradicals contribute to the peroxidation of lipid membranes leading to organelle fragility and cellular toxicity. This process is thought to contribute to hepatocellular necrosis and/or apoptosis in the liver with the subsequent activation of hepatic satellite cells and the development of hepatic fibrosis and cirrhosis.

Hemochromatosis is an abnormal iron metabolism which could lead to the over pumping of iron to different tissues and without treatment, consequent organ failure and even death can occur. This excess iron storage could be associated to tissue damage. Early diagnosis, before liver cirrhosis; could result in a good survival. Neonatal hemochromatosis is a severe neonatal liver disease associated with extrahepatic siderosis and is one of the most common causes of liver failure in the neonatal period ${ }^{2,3,4}$.

\section{The case}

A preterm male neonate (35 weeks) was admitted to our neonatal ward with Intra uterine Growth Retardation (IUGR) and a birth weight of 1500 grams, delivered by cesarean section to a 21-years-old woman (Gravida 2, Para 2) with a history of oligohydramenious, and no other remarkable history during pregnancy. The previous sibling died in infancy due to prematurity and abdominal distention of unknown etiology. There was history of consanguinity between the mother and father. They did not do any further investigation to find out about the reason behind the death of their first child.

This baby boy was admitted due to prematurity, poor feeding, non tolerability to oral feeding and vomiting coffee ground materials in the first hours of birth. His APGAR in the first minute was reported to be $8 / 10$, height: $47 \mathrm{~cm}$, head circumstance: $33 \mathrm{~cm}$ and Respiratory rate: $50 / \mathrm{min}$.

On physical examination, he was hypotonic and hyporeflexic with normal vital signs. There was a cardiac murmur of I-II/VI intensity and no other remarkable findings.

He turned icteric gradually to a grayish icter.

An echocardiogram evaluation revealed to a small apical VSD and ASD. 
At the day of birth, he was worked up for sepsis. Primary laboratory results showed:

\begin{tabular}{|c|c|c|c|c|}
\hline $\mathrm{FPG}=280 \mathrm{mg} \%$ & $\begin{array}{l}\text { Bilirubin total: } 2.5 \mathrm{mg} / 100 \\
\text { Bilirubin direct: } \\
0.3 \mathrm{mg} / 100 \\
\end{array}$ & $\begin{array}{l}\text { ABG: } \\
\text { PH:7.36,PCo2:24,PO2:172,H } \\
\mathrm{CO}_{3}: 13, \mathrm{SO}_{2}: 99 \%, \mathrm{ABE}:-11\end{array}$ & $\begin{array}{l}\text { Serum Ferritin of } \\
1458 \mathrm{mcg} / \mathrm{L}\end{array}$ & $\begin{array}{l}\text { Tripsin activity (titer) } \\
\text { was } 1 / 12 \text { (Normal: } \\
>1 / 192 \text { ). }\end{array}$ \\
\hline Urea=13 mg\% & Cr: $0.6 \mathrm{mg} \%$ & $\begin{array}{l}\mathrm{Na}: 131 \mathrm{meq} / \mathrm{L}, \mathrm{K}: 4.5 \mathrm{meq} / \mathrm{L} \text {, } \\
\text { Ca:7mg\% }\end{array}$ & $\begin{array}{l}\text { Stool Exam: } \\
\text { Moderate fatty } \\
\text { droplets seen. } \\
\end{array}$ & \\
\hline WBC: $4 \times 10^{3}$ & Poly:52\%, Lym:48\%, & & & PIt: $149 \times 10^{3}$ \\
\hline $\mathrm{Hb}: 9.1 \mathrm{gm} \%$ & RBC: $2.55 \times 10^{6}$ & ESR:2 mm/h & G6PD:Sufficient & MCV:104.3 \\
\hline HCT:26.6\% & CRP:1 & Retic:3.7\% & & \\
\hline
\end{tabular}

Direct Bilirubin increased gradually from 9 to 18 . Patient was evaluated with an impression of cholestasis which revealed normal liver enzymes and increased after that. A decreased serum albumin, protein and impaired coagulation tests with a colorless stool were found there after.

In this workup for cholestasis; Hypothyroidism, hepatitis $\mathrm{B}, \mathrm{TORCH}$ and sepsis were evaluated which revealed negative results. In the radiologic evaluations for biliary duct atresia; liver and biliary duct sonography was done. Gallbladder wall was thickened and edematous (due to hypoproteinemia), normal spleen and pancreas, and some free fluid in Morison space were detected. Fatty liver and Cirrhosis were among the top list for differential diagnosis.

Metabolic disorders were worked up in the infant. After further evaluation for cholestasis, idiopathic neonatal hemochromatosis was diagnosed at the top list.

Serum ferritin was reported 1500, therefore liver biopsy was considered in the $2^{\text {nd }}$ week of life. Histopathologic evaluation revealed to iron overload and idiopathic neonatal hemochromatosis was confirmed. Liver biopsy was suggestive for neonatal iron overload. Giant cell changes, clear sedimentation of gold-brown pigments in hepatocytes and sinosoides, mild necrosis and fibrosis in periportal and over central vein were detected. Unfortunately, this neonate died in 24-hours after biopsy.

\section{Discussion}

From the initial description of neonatal hemochromatosis in 1975, more than 100 cases have been reported so far $^{3}$. One study in North America showed that this condition is very common in the white population. Hemochromatosis gene affects men and women equally ${ }^{2}$.

There is an approximately $80 \%$ probability that when a woman gives birth to an infant suffering from neonatal hemochromatosis, her subsequent pregnancies will be affected too. Thus it was hypothesized that there is a linkage to an autosomal recessive inheritance or a gestational alloimmune disorder. Although no clear etiology is identified in most patients and it is considered as an idiopathic disease ${ }^{3}$.

Neonatal hemochromatosis could not be easily confirmed by standard biochemical, hematologic, or genetic tests. It is a severe multiorgan disease of perinatal onset associated with extrahepatic siderosis. Most live-born patients exhibit evidence of in-utero insult (intra-uterine growth retardation and oligohydramnios) and many are born premature. Untreated, neo-natal hemochromatosis is often fatal ${ }^{5}$.

Diagnosis of neonatal hemochromatosis could be achieved after ruling out other causes of liver failure. In this disease, serum level of ferritin is extremely high and there is hepatic and extrahepatic siderosis ${ }^{3}$.

Early recognition of neonatal hemochromatosis is vital for the infant and should be considered in neonatal liver failure.

\section{References}

1. Ramm GA, Ruddell RG. Iron Homeostasis, Hepatocellular Injury, and Fibrogenesis in Hemochromatosis: The Role of Inflammation in a Noninflammatory Liver Disease. Semin Liver Dis 2010;30(3):271-87.

2. Neville Regan E. Hemochromatosis. The Nurse Practitioner 2009;34(6):25-9.

3. Pearson L, Bissinger R, Romero KR. Neonatal Hemochromatosis, A Case Report. Adv Neonatal Care 2009; 9(2):72-6.

4. Pearson L, Bissinger R, Romero KR. Neonatal hemochromatosis: a case report. Adv Neonatal Care 2009;9(2):72-6.

5. Sifuentes Saenz M, Van Hove J, Scharer G. Neonatal liver failure: a genetic and metabolic perspective. Curr Opin Pediatr 2010; 22:241-45.

How to cite this article?

Besharat S, Alaee E, Zahedpasha Y. Idiopathic Neonatal Haemochromatosis: A Case Report. J Nepal Paediatr Soc 2011;31(3):247-248. 